\title{
Kajian Kehadiran Inang Primer pada Pertumbuhan Semai Cendana
}

\author{
Analysis of Primary Host Presence on Sandalwood Seedling Growth
}

\author{
Albertus Husein Wawo
}

Bidang Botani, Puslit Biologi-LIPI, Jl. Haji Juanda 22 -24, Bogor. 16122, E-mail: herbogor@indo.net.id

\begin{abstract}
Sandalwood (Santalum album L.) is known as a fancy plant. Since they have high economic value, it often over exploited. As a consequence, the population dramatically decreased in their habitats. Some efforts have been done to conserve this plant in order to prevent their extinction, i.e. seedling multiplication. As a hemiparasitic plant, sandalwoods need other plants for a host which grow around. Therefore, determining of the the primary host is a necessary aspect in multiplication of sandalwood seedling. This study used three species plants to serve sandalwood seedling as primary host in pot cultures consist of local leucaena (Leucaena glauca), vilosa (Acacia villosa) and calliandra (Calliandra calothyrsus). The results of this study indicated that $A$. vilosa is better for a primary host than L. glauca and $C$. calothyrsus as well. Number of root connection between sandalwood seedlings and their hosts have a close correlationship to the leaf number and the sandalwood seedling dry weight, whereas no significant correlationshifp to their height.
\end{abstract}

Key words: sandalwood, seedling multiplacation, primary host

Diterima: 17 September 2003, disetujui: 10 Januari 2004

\section{Pendahuluan}

Cendana (Santalum album L.) adalah salah satu komoditi penting dari Propinsi Nusa Tenggara Timur (NTT), dengan kantongkantong produksi utamanya di pulau Timor dan Sumba. Di pulau Sumba, populasi cendana dari tahun ke tahun mengalami penurunan karena kebakaran hutan, pemusnahan semai, perusakan dan pemotongan liar pohon, penyempitan kawasan hutan dan eksploitasi besar-besaran. Upaya untuk mencegah kepunahan cendana antara lain melalui konservasi ex situ maupun in situ.

Salah satu rantai dalam konservasi cendana adalah pengadaan bibit bermutu melalui tahapan pemilihan media semai, penyemaian benih dan pemilihan jenis inang primer yang sesuai. Tumbuhan inang sangat penting bagi cendana yang bersifat hemi parasitik sebagai pemasok unsure hara bagi pertumbuhan cendana. Inang primer dibutuhkan pada tahap pesemaian dan berpotensi untuk berkembang menjadi inang sekunder (permanen) ketika cendana hidup di lapangan. Pengelompokan jenis inang hanya dapat dilakukan cendana budidaya dan sulit dilakukan pada cendana alami di hutan.

Kriteria inang pada tumbuhan cendana adalah jika terjadi hubungan akar cendana dengan dan akar tumbuhan inang yang ditandai oleh kehadiran titik sambung akar (TSA) (Wawo, 2002). TSA terjadi karena haustorium akar cendana melekat pada akar inang untuk mengambil yang dibutuhkan seperti Nitrogen, Kalium dan Fosfor (Rai, 1990).

Fox and Barret (1994) melaporkan bahwa pertumbuhan haustorium sangat bervariasi dan tergantung pada jenis inang yang didapatkan setelah 6 minggu benih berkecambah. Dalam penelitian budidaya pot diketahui bahwa jenis inang akan menentukan pertumbuhan semai cendana (Rai, 1990). Fox, et. Al. (1994) telah melaporkan bahwa 
tumbuhan Desmanthus virgatus merupakan inang terbaik untuk semai cendana yang tumbuh dalam pot selama 3-4 tahun, didasarkan pada pertumbuhan semai cendana tanpa memperhatikan TSA pada akar $D$. virgatus. Penelitian TSA pada akar inang yang mempengaruhi pertumbuhan cendana baik pada tingkat semai maupun tanaman dewasa belum banyak dilakukan karena hambatan berbagai faktor fisik seperti media tumbuh yang padat dan keras sehingga akarnya mudah putus.

Penelitian ini bertujuan untuk mengetahui hubungan antara pertumbuhan semai cendana dengan kehadiran titik sambung akar pada tiga jenis tanaman yang digunakan sebagai inang primer yaitu $L$. glauca, A.. villosa, dan C. calothyrsus. Selain itu juga untuk mengetahui inang primer yang paling cocok untuk cendana dari ketiga jenis tumbuhan tersebut.

\section{Metode Penelitian}

Penelitian dilakukan di Kampung Kalela, Desa Maka Menggit, Kecamatan Nggaha Ori Angu, Kabupaten Sumba Timur NTT mulai bulan Juni hingga September 2002. Setelah direndam dalam air selama 12 jam biji cendana disemai dalam polybag berukuran $15 \mathrm{~cm} \times 15 \mathrm{~cm}$ yang berisi campuran tanah hitam dan pasir (1:1) yang telah ditaburi insektisida Furadan.

Kira-kira 30 hari setelah disemai, biji cendana mulai berkecambah dan pada saat bersamaan disemai pula benih tiga jenis tumbuhan inang primer cendana masingmasing lamtoro lokal (L. glauca), Akasia ( A. villosa) dan kaliandra (C. callothyrsus). Setiap polybag berisi semai cendana ditanami hanya satu butir benih inang dengan jarak 5,0 $\mathrm{cm}$ dari semai cendana. Rata-rata benih inang tersebut berkecambah selama 3-4 hari setelah disemai. Polybag yang berisi semai cendana dan inangnya diletakkan di bawah naungan yang terbuat dari daun kelapa dengan intensitas cahaya sekitar $50 \%$. Penyiraman dilakukan sekali dalam sehari dan pembersihan gulma.dilakukan sekali dalam sebulan.

Pengamatan tinggi semai, jumlah daun dan jumlah TSA, dilakukan 3 bulan setelah penyemaian inang. TSA diamati dengan cara membongkar media semai secara berhati-hati dalam air untuk mengurangi kerusakan akar cendana dan akar inang. TSA adalah titik sambung akar yang merupakan lokasi pertemuan antara haustorium cendana dengan akar inang. Berat kering semai cendana diperoleh dengan cara mengeringkan dengan oven bagian semai yang hidup di atas permukaan tanah. Semai dipotong menjadi ukuran yang lebih kecil dan dimasukkan dalam oven pada suhu $120^{\circ} \mathrm{C}$ selama 24 jam.

Uji hubungan antara jumlah TSA dengan tinggi semai cendana, jumlah daun dan berat kering semai menggunakan analisis Regresi dan Korelasi (Gomez and Gomez, 1995)

\section{Hasil dan Pembahasan}

\section{Pertumbuhan Semai Cendana dan Inang}

Hasil pengamatan pertumbuhan semai cendana dan jenis inang tertera pada Tabel 1 .

Tabel 1. Rata-rata pertumbuhan cendana dan Inangnya pada umur semai 3 bulan .

\begin{tabular}{lcc}
\hline \hline Cendana dan Jenis Inang & Tinggi Semai $(\mathbf{c m})$ & Jumlah Daun \\
\hline \hline Cendana & 7,06 & 4,25 \\
Lamtoro & 9,00 & 9,60 \\
Cendana & 8,55 & 5,90 \\
Akasia & 8,85 & 8,80 \\
Cendana & 6,33 & 6,00 \\
Kaliandra & 4,00 & 6,66 \\
\hline \hline
\end{tabular}


Semai cendana tertinggi diperoleh pada semai yang tumbuh bersama inang akasia, sedangkan jumlah daun terbanyak terdapat pada semai dengan inang kaliandra dan akasia. Pertumbuhan tinggi dan jumlah daun semai cendana selain ditentukan oleh vigor benih dan naungan pada tempat semai juga dipengaruhi oleh inang yang mendampingi semai cendana tersebut. Hal ini sesuai dengan pendapat Rai (1990) yang mengatakan pertumbuhan semai cendana dalam pot ditentukan juga oleh jenis inang yang ada. Sementara itu Suriamihardja, et. al.
(1991) mengatakan bahwa pertumbuhan tinggi dan jumlah daun semai cendana dipengaruhi pula oleh jenis inang. Pendapat yang sama juga dikemukakan oleh Surata (1992) bahwa pertumbuhan tinggi, diameter dan bobot kering semai cendana pada umur 7 bulan juga bervariasi dan tergantung pada inang primernya.

Hasil pengamatan jumlah TSA dan berat kering semai cendana diperlihatkan pada Tabel 2 berikut.

Tabel 2. Rata-rata jumlah TSA dan berat kering semai cendana

\begin{tabular}{lll}
\hline \hline Jenis inang & Jumlah TSA (unit) & Berat kering $(\mathbf{m g})$ \\
\hline \hline Lamtoro & 0,75 & 40,75 \\
Akasia & 1,80 & 184,00 \\
Kaliandra & 1,00 & 70,00 \\
\hline \hline
\end{tabular}

Pada Tabel 2 terlihat bahwa rata -rata jumlah TSA terbanyak terdapat pada inang akasia sedangkan berat kering semai cendana tertinggi terdapat pada semai cendana yang tumbuh bersama inang akasia. Penelitian Rai (1990) di India juga menunjukkan variasi antara jumlah TSA dan berat kering semai cendana dengan jenis inang primernya. Mindawati (1987) menerangkan berat kering batang dan daun pada semai cendana sangat bervariasi tergantung pada inang primernya. Badan Penelitian dan Pengembangan Kehutanan (1992) melaporkan bahwa akar cendana dapat menggapai akar inang selain dipengaruhi kondisi fisik tanah juga kecocokannya seperti kelunakan akar dan kelembaban kulit akar inang. Kesuksesan hubungan akar tersebut ditunjukkan melalui tinggi semai dan jumlah daun semai cendana (Tabel 1), yang memberikan berat kering tertinggi pada semai cendana. Keunggulan akasia dari dua jenis inang lain diduga terletak pada tekstur akarnya sehingga akar semai cendana lebih mudah melakukan hubungan.

\section{Hubungan TSA dan Pertumbuhan semai.}

Hubungan jumlah TSA dengan berbagai variabel pertumbuhan semai cendana seperti tinggi semai (TT), jumlah daun (JD) dan berat kering (BK) akan diuraikan sebagai berikut; Analisis Regresi dan Korelasi antara Jumlah TSA pada akar inang dengan tinggi semai cendana diperoleh pesamaan Regresi linier sederhana sebagai berikut :

$$
\begin{aligned}
& \mathrm{Y}=0,2734 \mathrm{X}+7,3151 \text { dengan nilai } \\
& \text { koefisien korelasi } \mathrm{R}^{2}=0.0363 .
\end{aligned}
$$

Nilai koefisien korelasi $\mathrm{r}$ hitung sebesar 0,19 $\left(\mathrm{R}^{2,}=0,0363\right)$ lebih kecil dari $\mathrm{r}$ tabel pada taraf uji 5\% sebesar 0,433 (Gomez and Gomez, 1995) menunjukkan hubungan yang tidak erat antara jumlah TSA dengan tinggi semai cendana. Ketidakeratan ini disebabkan oleh umur semai yang relatif muda sehingga tinggi semai masih terbatas. Selanjutnya hubungan antara jumlah TSA dengan jumlah daun semai cendana diperlihatkan pada Gambar 1. 


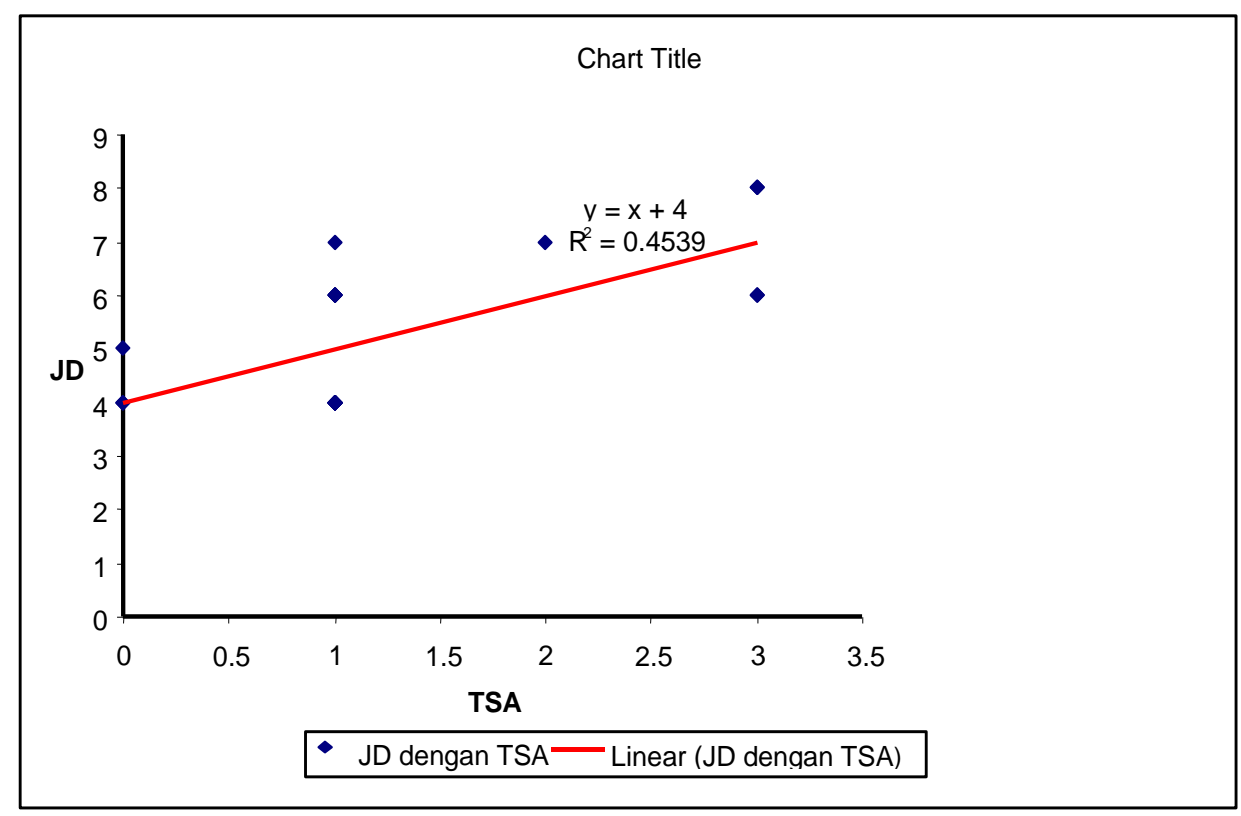

Gambar 1. Hubungan TSA dengan jumlah daun cendana

Gambar 1 menunjukkan ada hubungan yang erat antara jumlah TSA pada akar inang dengan jumlah daun semai cendana. Hubungan yang erat ini ditandai dengan nilai koefisien korelasi $r$ hitung sebesar 0,67 lebih besar dari nilai $\mathrm{r}$ tabel pada taraf uji $5 \%$ sebesar 0,433 (Gomez and Gomez, 1995). Hubungan yang erat tersebut menunjukkan peranan TSA dalam pertumbuhan daun semai cendana.

Gambar 2 memperlihatkan hubungan jumlah TSA dengan berat kering semai cendana.

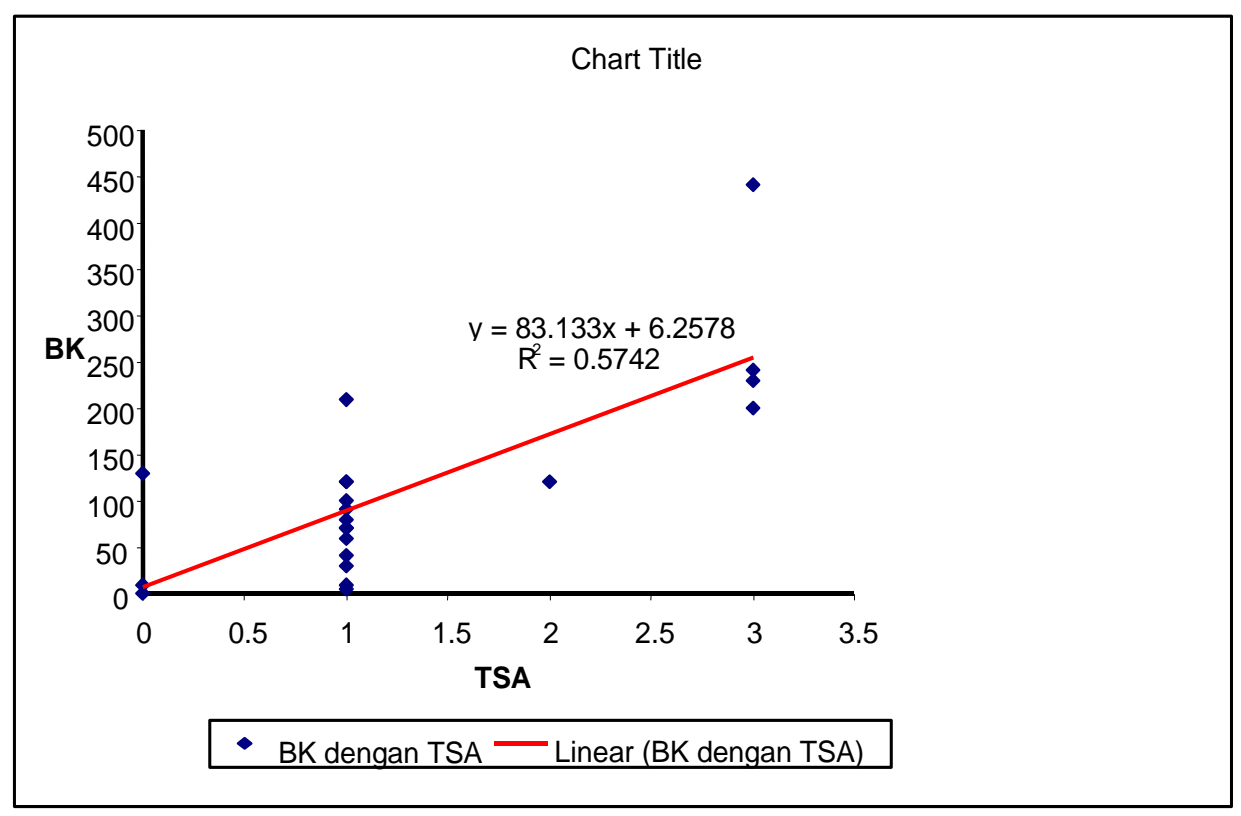

Gambar 2. Hubungan TSA dengan berat kering cendana 
Gambar 2 juga menunjukkan bahwa jumlah TSA pada akar inang memiliki hubungan yang erat dengan berat kering (BK) semai cendana. Hubungan yang erta ini juga ditunjukkan melalui nilai koefisien korelasi $\mathrm{r}$ hitung sebesar 0,75 lebih besar dari nilai $\mathrm{r}$ tabel pada taraf uji 5\% sebesar 0,433 (Gomez and Gomez, 1995). Penyebab hubungan yang erat antara jumlah TSA dengan berat kering semai karena TSA juga memberi pengaruh positif pada pertumbuhan jumlah daun .

\section{Kesimpulan} disimpulkan :

Dari hasil penelitian ini dapat

1. Akasia (Acacia villosa) merupakan inang primer yang lebih sesuai untuk semai cendana yang tumbuh dalam polybag. daripada kaliandra dan lamtoro lokal.

2. Jumlah TSA pada akar inang memiliki hubungan yang erat dengan pertumbuhan daun dan berat kering semai cendana pada umur 3 bulan, tetapi tidak berpengaruh nyata pada pertumbuhan tinggi semai cendana.

\section{Daftar Pustaka}

Badan Penelitian dan Pengembangan Kehutanan. 1992. Buku Pintar Cendana (Santalum album Linn). No. 07 / II / 92. Departemen Kehutanan.

Fox, J.E.D. and Barrett, D.R., 1994. Silvicultural Charateristics Associated with Ecology and Parasitics Habit of Sandalwood. Dalam Sandalwood Seed, Nursery and Plantation Terchnology. Proceedings of A Regional Workshop for Pacific Island Countries. Noumea- New Caledonia. Organized and sponsored by Cirad Foret New Caledonia, ACIAR and South Pacific Forestry Development Prgramme.
Fox, J.E.D., Doronila, A.I, Barrett, D.R. and Surata, I.K., 1994. The Selection of Superior Pot Hosts for Maximum Nursery Growth in Santalum album Dalam Sandalwood Seed, Nursery and Plantation Terchnology. Proceedings of A Regional Workshop for Pacific Island Countries. Noumea- New Caledonia. Organised and sponsored by Cirad Foret New Caledonia, ACIAR and South Pacific Forestry Development Prgramme.

Gomez, K.A. and Gomez, A. A., 1995. Prosedur Statistik Untuk Penelitian Pertanian. Edisi Kedua. Penerjemah: E. Syamsuddin \& J.S. Baharsjah. UI. Press.

Mindawati, N., 1987. Pengaruh Beberapa Tanaman Inang Terhadap Pertumbuhan (Santalum album L.). Buletin Peneltian Kehutanan. No. 492. Bogor.

Rai, S.N., 1990. Status and Cultivation of Sandalwood in India. Dalam: Proceedings of the Symposium on Sandalwood in the Pacific . Honolulu, Hawaii. General Technical Report. PSW-122. United States, Department of Agriculture, Forest Service. Pacific Southwest Research Station.

Surata, I. K., 1992. Pengaruh Jenis Inang Terhadap Pertumbuhan Semai Cendana (Santalum album). Santalum. No. 9. Buletin Penelitian Dan Pengembangan Kehutanan Nusa Tenggara Dan Maluku Tenggara. Kupang.

Suriamihardja, S., Surata, I.K. dan Kharisma, 1991. Pengaruh Varietas, Urea dan Inang Terhadap Pertumbuhan Semai Cendana ( Santalum album L.). Santalum. No. 6.

Buletin Penelitian Dan Pengembangan Kehutanan Nusa Tenggara Dan Maluku Tenggara. Kupang.

Wawo, A.H., 2002. Studi Morfologi dan Anatomi Hubungan Akar Cendana Dengan Akar Inangnya Di Pulau Timor - NTT. Makalah II. Dalam : Tesis S2 Keanekaragaman Jenis Pohon Yang Didiga Sebagai Inang Sekunder Cendana Di Pulau Timor - Nusa Tenggara Timur. Program Studi Biologi Konservasi. FMIPA - UI. 